\title{
Moving targets: collective decisions and flexible choices in house-hunting ants
}

\author{
Nigel R. Franks • James W. Hooper • Mike Gumn • \\ Tamsyn H. Bridger · James A.R. Marshall • \\ Roderich Groß • Anna Dornhaus
}

Received: 4 May 2007 / Accepted: 21 September 2007

(C) Springer Science + Business Media, LLC 2007

\begin{abstract}
Many decisions involve a trade-off between commitment and flexibility. We show here that the collective decisions ants make over new nest sites are sometimes sufficiently flexible that the ants can change targets even after an emigration has begun. Our findings suggest that, in this context, the ants' procedures are such that they can sometimes avoid 'negative information cascades' which might lock them into a poor choice. The ants are more responsive to belated good news of a higher quality nest than they are when the nest they had initially chosen degraded to become worse than an alternative. Our study confirms, in a new way, that ant colonies can be very powerful "search engines".
\end{abstract}

Keywords Social insects · Decision-making $\cdot$ Information cascades · Multi-tasking $\cdot$ Nest choice $\cdot$ Temnothorax albipennis

\section{Introduction}

One advantage of living in a society is greater access to timely and accurate information (Couzin et al. 2005). Members of a society may gain information from one another about sources of forage; predators and other dangers; or realms of relative safety such as communal roosting or nesting sites (King and Cowlishaw 2007). Alternatively, misinformation could, in principle, cascade through a society so that collective decisions might be poor and inflexible (Giraldeau et al. 2002). In addition, for both individuals and groups there may be speedaccuracy trade-offs because gathering information takes time whereas poorly informed decisions may be error prone (Chittka et al. 2003, Franks et al. 2003a; Marshall et al. 2006; Pratt

N.R. Franks $(\bowtie)$ J.W. Hooper · M. Gumn · T.H. Bridger · R. Groß · A. Dornhaus School of Biological Sciences, University of Bristol, Woodland Road, Bristol, BS8 1UG, UK e-mail: nigel.franks@bristol.ac.uk

J.A.R. Marshall

Department of Computer Science, University of Bristol, Bristol, UK

Present address:

A. Dornhaus

Ecology and Evolutionary Biology, University of Arizona, Tucson, USA 
and Sumpter 2006). Moreover, sampling information may take time from other activities. So there is likely to be a need for a trade-off between exploration and exploitation (Janson et al. 2007). Similarly, a suitable compromise is likely to be needed between individual exploitation of resources and informing others about them (Dechaume-Moncharmont et al. 2005; Dornhaus et al. 2006).

The ability of insect societies to switch their choice of targets at the collective level has been intensely investigated in foraging honey bees (Seeley 1995); in foraging ants that lay pheromone trails to food sources (Beckers et al. 1990, 1992; see also Camazine et al. 2001 for a review) and in house hunting honey bees (Seeley and Buhrman 1999; Britton et al. 2002). In this study, we investigate whether the collective decisions made by house-hunting ants are sufficiently flexible that they can change target even after they have selected one and begun to emigrate to it, or if they are too constrained by their communication systems and the limited local information available to individuals to be able to make, and take advantage of, new and better discoveries.

Social insect colonies can benefit from the information gathered by the many brains of their distributed members (Franks 1989) and are one of the best examples of swarm intelligence in biology. Social insect colonies are also ideal study systems because the various information and communication trade-offs mentioned above are often visible and quantifiable because they are represented in the physical deployment of workers to different localities. In principle, colonies might also be the perfect paradigm of multi-tasking. Each individual should be able to focus almost completely on the task or information that confronts them locally while concurrent tasks are left to others. Though even here, communication channels should be kept open so that individuals can exchange signals about changing priorities.

It is precisely because of their sophisticated information-processing abilities that engineers have recently drawn inspiration from the collective decision making processes employed by social insects, applying them to solve combinatorial optimization problems and control problems in engineering (Bonabeau et al. 1999). Perhaps, at least partly, because of this increased interest from non-biologists, much recent research has focused on collective decision making in social insects, especially house-hunting by rock ants (Temnothorax albipennis) and honey bees (Apis mellifera) (Visscher 2007). In both cases, individuals gather substantial data sets about potential nest sites and then the society is able collectively to choose the best available site by using opinion polling procedures such as quorum sensing (Pratt et al. 2002). Such is the power and efficiency of this form of decision making that honey bees, for example, can select the best nest site even if news of it arrives late in the decision-making process (Seeley and Buhrman 1999; see also Britton et al. 2002 for a mathematical model of this process). As with other social insect behaviors, house-hunting has also attracted the attention of engineers (Peysakhov and Regli 2005; Cicirello et al. 2005; Peysakhov et al. 2006; Berman et al. 2006, 2007). In this paper, we will investigate experimentally if house-hunting T. albipennis ants can respond to new information that arrives late. This is a highly relevant question both for the social insects, who inhabit a highly unpredictable dynamic environment, and for engineers seeking optimal control algorithms for similarly difficult problems.

House-hunting in the rock ant Temnothorax albipennis is one of the most intensively and extensively studied systems of collective decision-making in non-human animals (Conradt and Roper 2005; Visscher 2007). In T. albipennis, each colony has a single queen and up to about 400 workers as well as brood (eggs, larvae and pupae) that the colony has to rear (Franks et al. 2006a). The members of a colony are not clones. In ants, males are haploid and females (queens and workers) are diploid. So if a colony has a single queen, who is singly mated, (as is typical in T. albipennis, Pearson et al. 1995) all of the workers will be so-called 
supersisters (with an average co-efficient of relatedness of 3/4) (Bourke and Franks 1995). This is higher than the $1 / 2$ relatedness of full siblings in a fully diploid species (hence the term supersisters) because full sister ant workers receive an identical set of genes from their haploid father. Thus workers should gain (inclusive) fitness by co-operating to achieve high group-level efficiency, because of their close relatedness to other colony members (Bourke and Franks 1995).

In nature, T. albipennis colonies nest in thin and relatively flat crevices in rocks. This means that whole colonies can be collected relatively easily. The colonies and their members are so small that they can be housed, in a good approximation to their natural geometry, in nests made by sandwiching a cardboard gasket between a pair of microscope slides. Typically, we make such nests with a single entrance to a single cavity, with an area of a few centimeters squared, within the cardboard. Such laboratory nests allow us to observe all the members of the society. That is, we can rather easily observe "all of the players all of the time". Nest sites in nature are fragile and ephemeral and colonies probably need to move frequently to new homes. In the laboratory we can present colonies with a range of alternative nest sites in a relatively small arena and provoke an emigration by removing the top microscope slide of their current nest. In this way, we have been able to analyse not only which nests they prefer but also, by observing the individual workers that do all of the scouting for new homes, how they influence one another during the decision-making process and recruit their nest mates into an emigration to the chosen new nest site (Franks et al. 2002).

In $T$. albipennis ants, individual scouts pause for longer before recruiting to poor nests than they do for good nests (Mallon et al. 2001). Such hesitation will discriminate against nests of low quality because snowballing recruitment to better nests will begin sooner. The first form of recruitment by scouts is typically by tandem-running. In this process, one ant that knows the location of the new nest returns to the old nest and leads a nest mate back to the new one. Tandem leaders literally teach their followers how to find the new nest by giving them a highly structured learning opportunity as both pass along the route to the new nest (Franks and Richardson 2006). Tandem running is very slow and typically it is soon replaced by recruitment through social carrying which is about three times faster (Pratt et al. 2002). The switch from tandem running to carrying occurs when the ants achieve a quorum in the new nest site. Quorum thresholds vary, but often they are associated with scouts finding about 12 nest mates in the nest site (Pratt et al. 2002). This number is sufficiently high that all of these workers are unlikely to have been lead to the new nest site by the same scout. For this reason, such quorums imply that several ants independently have found the new nest site acceptable. Quorum sensing is a method of collating the independent "opinions" of several individuals. Building a quorum should help to promote a unified decision and hence one might assume that once carrying has begun a colony is fully committed to that new nest site and no further search or switching is possible (Planqué et al. 2006). Here we test this assumption.

We investigate experimentally the abilities of Temnothorax albipennis ants to change the nest site they select after a decision has been made; that is during the emigration process. In one set of experiments, we introduced a better nest after the ants had started to emigrate to one of lower quality. In the other set of experiments, the ants could choose between simultaneously presented high quality and low quality nests. However, after they had started to emigrate to the high quality nest, we degraded it so that it was of lower quality than the alternative. Both sets of experiments tested the ability of the ants to switch target after a decision had been made. Colony size can be influential in house-hunting decisions in T. albipennis (Franks et al. 2006a; Dornhaus and Franks 2006). Larger colonies deploy more scouts and may use a correspondingly higher quorum threshold; scouts discovering the new 
nest independently also play a larger role, whereas small colonies rely more on experienced scouts recruiting other ants. Therefore, we also tested for colony size effects on the ability to switch. Hence we investigated the potential abilities of social insects to continue to search for better alternatives even when they had apparently committed themselves collectively to a particular choice.

\section{Methods}

The ant colonies were collected from Dorset, England. Emigrations took place in $220 \times$ $220 \times 22 \mathrm{~mm}$ Petri dishes. Basic details of our experimental techniques are given in Franks et al. (2003b).

We used nests of three different qualities (see Franks et al. 2003b). All had internal cavity dimensions of $33 \times 55 \mathrm{~mm}$, were cut out of pieces of card that were $50 \times 70 \mathrm{~mm}$, and were sandwiched between two glass microscope slides. All had an entrance of $2 \mathrm{~mm}$ width and $5 \mathrm{~mm}$ length. A mediocre nest had a cavity height of $1.1 \mathrm{~mm}$ and was light; a good nest had a cavity of height $1.8 \mathrm{~mm}$ and was light; and a deluxe nest had a cavity height of $1.1 \mathrm{~mm}$ and was made "dark" for the ants with a red filter (Franks et al. 2006b). Such a deluxe nest is preferred by the ants to the good nest, which in turn is preferred to the mediocre nest (Franks et al. 2003b).

Colonies were given a choice between two nests in each emigration (Fig. 1). The two nests were randomly assigned to the left and right side of the arena. An emigration was initiated by the removal of the top slide of the currently occupied nest. This caused the occupants to search for a new nest.

The numbers of adults (i.e. workers plus the single queen) and brood in each nest was determined at 10 minute intervals by counting in situ. Where possible we did this for the first 3 hours following destruction of the old nest. In some cases, such recordings were made for slightly shorter or longer times.

Final nest occupancy was determined $24 \mathrm{hrs}$ after the start of each experiment and control. Split colonies were defined as those that had one or more brood items in both nests at the end of the experiment.

Fig. 1 The arena layout in all experiments and controls after all quality changes had occurred

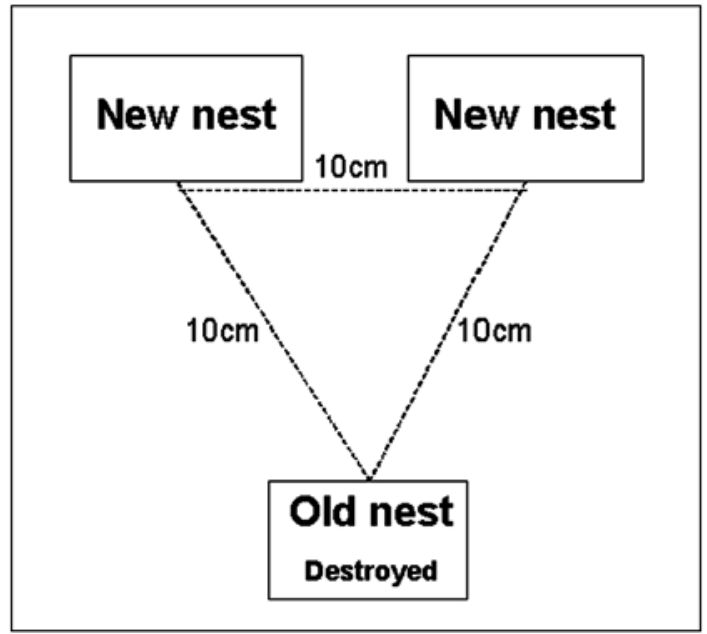


Two experiments and three controls were designed to test key hypotheses by specific comparisons that were determined a priori. We quantified how much inertia vs. flexibility the colonies exhibited when news of a better nest was only available late (comparison of experiment 1 and control 1). We tested whether the quality of a novel nest is assessed (comparison between experiment 1 and control 2). Finally, we determined the degree of inertia vs. flexibility when a high quality nest was degraded during an emigration (experiment 2 vs. control 3 and also experiment 2 vs. control 1).

Experiment 1 Colonies began their emigrations in an arena with a single mediocre nest site made available after the old nest was destroyed. Five minutes after the start of carrying (of either adult or brood items) to the mediocre nest a good nest was introduced. This setup tested whether the collective decision process, once initiated, could be re-oriented to a different, higher quality target.

Experiment 2 Colonies began their emigrations in an arena with both a deluxe and a good nest site available. Five minutes after the start of carrying to the deluxe nest, the red filter was removed from the deluxe nest to make it mediocre. In this condition, the ants had the opportunity to switch (or not) to a new target after the old, chosen target had degraded in quality.

Control 1 Colonies emigrated in an arena with a mediocre nest and a good nest present throughout.

Control 2 Colonies began their emigrations in an arena with a mediocre nest. Five minutes after the start of carrying to the first nest a second and identical mediocre nest was introduced to the arena.

Control 3 Colonies emigrated in an arena with a good nest and a deluxe nest present throughout.

\section{Results}

Overall, for the two experiments and three controls we ran a total of 174 colony emigrations.

Fisher's exact tests (all 2-tailed) were used to compare the results of each experiment and control as explained below. Only colonies that chose just one of the available nests were analyzed using Fisher's exact tests. So here split colonies were not compared. In addition, we used Chi-squared tests on each comparison between the experimental results and controls. These Chi-squared tests included the data on the colonies that had split. Comparisons of the Fisher's exact test results and the Chi-squared test results should reveal if the frequency of splitting colonies had any great influence, or not, on the overall patterns of association. Throughout all of the comparisons below the patterns revealed by the Fisher's exact tests and the Chi-squared tests are extremely similar. Thus the inclusion or exclusion of colonies that split does not influence the interpretation of the results.

We used certain data sets in two comparisons, so p-values were assessed according to the Benjamini Hochberg stepwise procedure (see Benjamini and Yekutieli 2001). This method is more sensitive than for example the Bonferroni correction that is commonly used for multiple comparisons. Using the Benjamini Hochberg procedure all of the comparisons for the data in Tables 1 through 4 were significant; thus, in each case the null hypothesis could be rejected. 
Table 1 The ability of ant colonies to switch their nest choice when a better alternative only becomes available after emigration to a worse one has begun. In the control, both alternatives are omnipresent so choices can be made without switching. The totals in bold within the cells are number (and percentage) of colonies

\begin{tabular}{llll}
\hline & Chose mediocre & Chose good & Split \\
\hline Experiment 1 & no switching & switching & \\
Late introduction of & $\mathbf{2 0}$ & $\mathbf{1 0}$ & $\mathbf{6}$ \\
good nest to arena with & $(\mathbf{5 5 \% )}$ & $\mathbf{( 2 8 \% )}$ & $\mathbf{( 1 7 \% )}$ \\
mediocre nest & & no switching & \\
Control 1 & no switching & $\mathbf{2 8}$ & $\mathbf{3}$ \\
$\begin{array}{l}\text { Omnipresent mediocre } \\
\text { and good nests }\end{array}$ & $\mathbf{1 7}$ & $\mathbf{( 5 8 \% )}$ & $\mathbf{( 6 \% )}$ \\
\hline
\end{tabular}

Table 2 The ability of ant colonies to switch their nest choice when a better alternative only becomes available after emigration to a worse one has begun. The results from the control imply that switching only occurs to nests of higher quality. The totals in bold within the cells are number (and percentage) of colonies

\begin{tabular}{|c|c|c|c|}
\hline & Switched & No switching & Split \\
\hline Experiment 1 & chose good & chose mediocre & \\
\hline $\begin{array}{l}\text { Late introduction of } \\
\text { good nest to arena with } \\
\text { mediocre nest }\end{array}$ & $\begin{array}{l}10 \\
(28 \%)\end{array}$ & $\begin{array}{l}\mathbf{2 0} \\
(55 \%)\end{array}$ & $\begin{array}{l}6 \\
(17 \%)\end{array}$ \\
\hline Control 2 & chose introduced mediocre & chose initially present mediocre & \\
\hline $\begin{array}{l}\text { Late introduction of } \\
\text { mediocre nest to arena } \\
\text { with mediocre nest }\end{array}$ & $\begin{array}{l}\mathbf{0} \\
(0 \%)\end{array}$ & $\begin{array}{l}21 \\
(64 \%)\end{array}$ & $\begin{array}{l}12 \\
(36 \%)\end{array}$ \\
\hline
\end{tabular}

A substantial minority of colonies were able to switch to a newly available better nest even though they had started to emigrate by carrying nest mates to an initially available (but lower quality) new nest site. Comparison of the results of experiment 1 and control 1 (Table 1) showed a significant association between treatment and outcome (Fisher's exact test: $p=0.0189$; Chi-squared test $=8.22, d f=2, p=0.016$ ). When the mediocre and good nests were omnipresent (control 1) more colonies chose the good nest, whereas in experiment 1, 20 colonies chose the ever present mediocre nest and 10 switched to the good nest which was a late introduction. Most colonies thus locked on to their initial target but a substantial minority switched.

Colonies did not switch to a later introduced nest purely on the basis of novelty: Of the colonies that chose only one nest in control 2 , none chose the mediocre nest that was a late introduction. Comparison of the results of experiment 1 and control 2 (Table 2) again showed a significant association between treatment and outcome (Fisher's exact test: $p=0.0031$; Chi-squared test $=11.92, d f=2, p=0.003)$. Hence, the 10 colonies that switched in experiment 1 probably did so to take advantage of a higher quality nest.

All colonies that chose a single nest chose the deluxe one when the good and deluxe nests were omnipresent (control 3). However, most of the colonies that initially chose the deluxe nest were unable to switch when that target became less valuable than the alternative. (Only 15\% were able to switch.) Nevertheless, comparison of the results of experiment 2 and control 3 (Table 3) showed a significant association between the treatments and the outcome (Fisher's exact test: $p=0.0308$; Chi-squared test $=7.13, d f=2, p=0.028$; N.B. this Chisquared test is included for completeness but it should be treated with caution as too many 
Table 3 The ability of ant colonies to switch their nest choice when the initially preferred nest is degraded, after emigration had begun, to become worse than an alternative. In the control, initial alternatives are omnipresent so choices can be made without switching. The totals in bold within the cells are number (and percentage) of colonies

\begin{tabular}{|c|c|c|c|}
\hline & Chose Good & $\begin{array}{l}\text { Chose } \\
\text { Deluxe/Mediocre }\end{array}$ & Split \\
\hline Experiment 2 & switched & no switching & \\
\hline $\begin{array}{l}\text { Deluxe nest degraded } \\
\text { to mediocre in an arena } \\
\text { containing a good nest }\end{array}$ & $\begin{array}{l}4 \\
(15 \%)\end{array}$ & $\begin{array}{l}17 \\
(63 \%)\end{array}$ & $\begin{array}{l}6 \\
(22 \%)\end{array}$ \\
\hline Control 3 & chose good & chose deluxe & \\
\hline $\begin{array}{l}\text { Omnipresent deluxe } \\
\text { and good nests }\end{array}$ & $\begin{array}{l}0 \\
(0 \%)\end{array}$ & $\begin{array}{l}27 \\
(90 \%)\end{array}$ & $\begin{array}{l}3 \\
(10 \%)\end{array}$ \\
\hline
\end{tabular}

Table 4 The ability of ant colonies to switch their nest choice when their initially preferred nest is degraded, after emigration had begun, to become worse than an alternative. In the control both final alternatives are omnipresent so choices can be made without switching. The totals in bold within the cells are number (and percentage) of colonies

\begin{tabular}{llll}
\hline & $\begin{array}{l}\text { Chose } \\
\text { Deluxe/Mediocre }\end{array}$ & Chose Good & Split \\
\hline $\begin{array}{l}\text { Experiment 2 } \\
\begin{array}{l}\text { Deluxe nest degraded } \\
\text { to mediocre in an arena }\end{array}\end{array}$ & $\mathbf{1 7}$ switching & switched & \\
$\begin{array}{l}\text { containing a good nest } \\
\text { Control 1 }\end{array}$ & $(\mathbf{6 3 \% )}$ & $\mathbf{4}$ & $\mathbf{6}$ \\
$\begin{array}{l}\text { Omnipresent good and } \\
\text { mediocre nests }\end{array}$ & i.e. chose mediocre & i.e. chose good & \\
\hline & $\mathbf{1 7}$ & $\mathbf{2 8}$ & $\mathbf{3}$ \\
\hline
\end{tabular}

of the cells have expected values of less than 5). This suggests that some colonies (albeit a small minority) did switch nests as a result of the deterioration in their initial choice.

Most colonies that chose a single nest chose the good one when a good and a mediocre nest were omnipresent (control 1). However, the vast majority of colonies that had begun to emigrate to a deluxe nest, which then degraded to a mediocre one, were unable to switch to the better (good) alternative. Comparison of the results of experiment 2 and control 1 (Table 4) showed a significant association between the treatments and the outcome (Fisher's exact test: $p=0.0014$; Chi-squared test $=14.24, d f=2, p=0.001$ ).

Through comparison of the experiments with the specifically relevant controls, it seems that there was substantially more switching in experiment 1 than experiment 2 (c.f. Tables 1 and 3). We therefore tested for an association between colony size (Franks et al. 2006a; Dornhaus and Franks 2006) and the ability of colonies to switch in experiment 1 . There was no such association (Mann-Whitney Test $W=284.0, p=0.2619$ ). Non-switching colonies had a median of 51.5 workers $(N=20$; inter-quartile range 35 to 101.5). Switching colonies had a median of 87.5 workers ( $N=10$; inter-quartile range 39.5 to 131.5$)$.

The percentage of colonies that split in the different experiments and controls may also provide some insights. In the treatments with a late introduction of an alternative, namely experiment 1 and control 2, the percentage of colonies that split is respectively $17 \%$ and $36 \%$. In experiment 2 where a change occurs in the relative quality of the two alternatives, the 

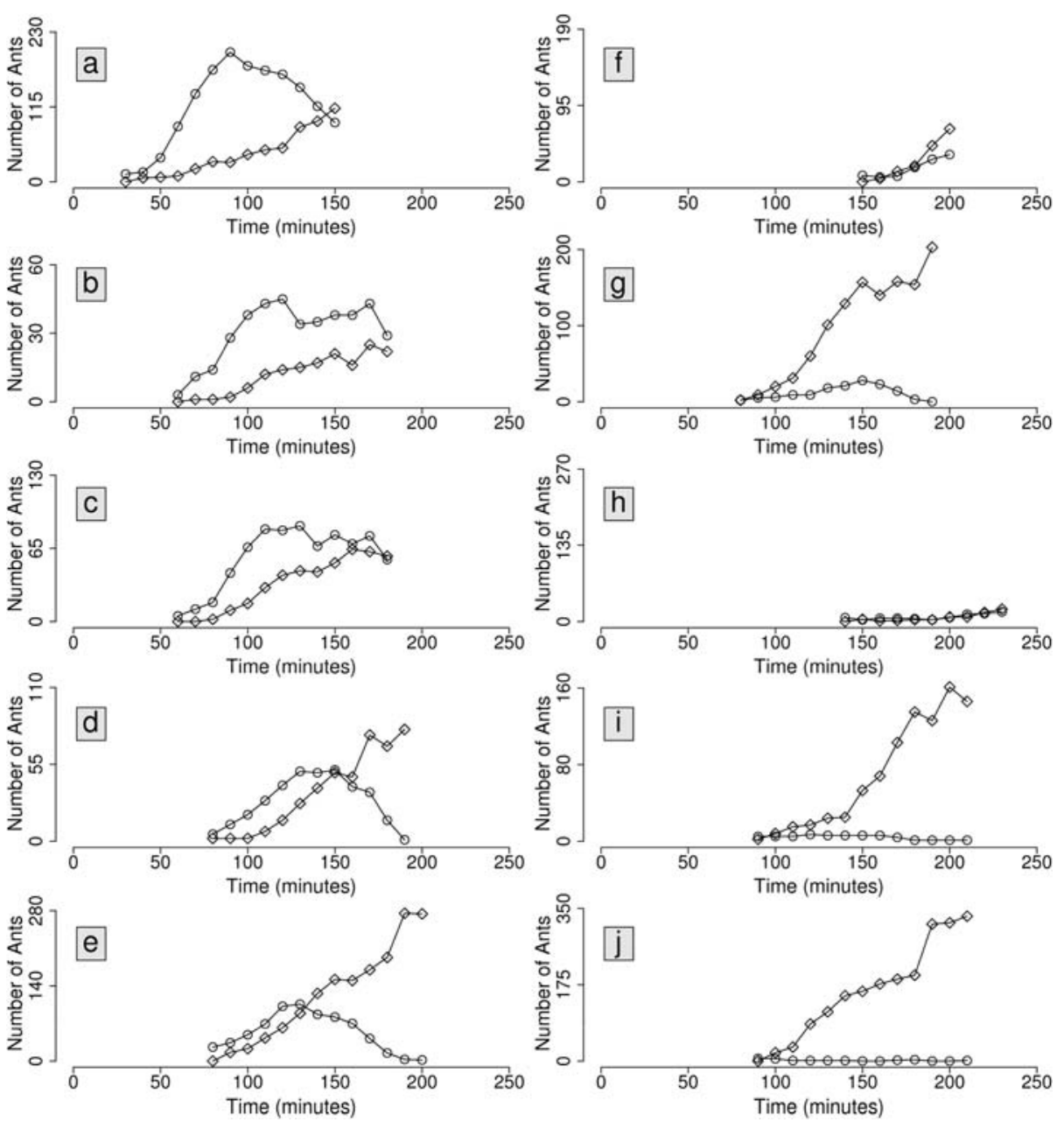

Fig. 2 Experiment 1 Nest occupancy data for the 10 colonies that were able to switch from emigrating to the mediocre nest to emigrating to the belatedly introduced good nest. The $x$ axis shows time in minutes. The old nest was destroyed at time 0 to initiate house hunting. The $y$ axis shows total (i.e. combined) numbers of adults and brood. Each graph depicts only the nest occupancy dynamics from the time at which the good nest was introduced. This was 5 minutes after carrying had begun to the mediocre nest. The number of ants occupying the mediocre nest is indicated with circles. The number of ants occupying the good nest is indicated with diamond-shaped symbols

percentage of the colonies that split is $22 \%$. In the treatments with a stable environment, namely control 1 and control 3, the percentage of colonies that split was respectively $6 \%$ and $10 \%$. It thus seems that any late change in the number or the quality of the different alternatives may be associated with a greater probability of colony splitting. Moreover, this supports the idea that colonies can be at least partly flexible since such splitting means that part of the colony was able to select the better alternative.

In both experiments 1 and 2, many of the colonies that were able to switch to the better, but belated, alternative nest did so by beginning to emigrate to that alternative even as the emigration to the first nest continued. Indeed, inspection of the data in Figs. 2 and 3 suggests 

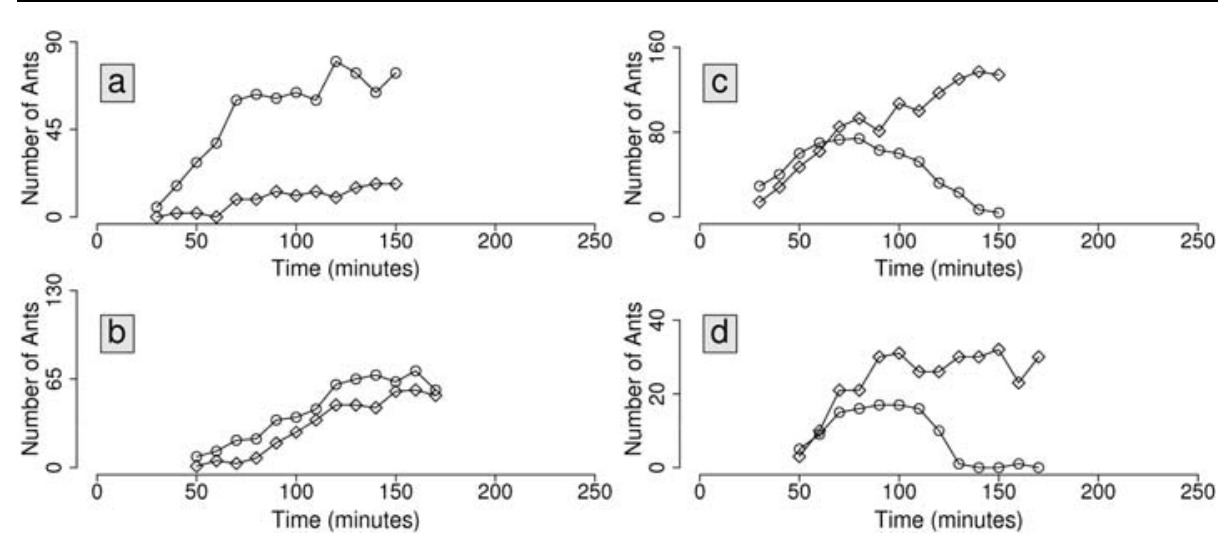

Fig. 3 Experiment 2 Nest occupancy data for the 4 colonies that were able to switch to a good nest after beginning an emigration to an initially deluxe nest that was experimentally degraded to a mediocre nest five minutes after carrying to it had begun. The alternative good nest was present throughout. This good nest was inferior to the initially deluxe nest but became the best nest available when the deluxe nest was made mediocre. The $x$ axis shows time in minutes. The old nest was destroyed at time 0 to initiate house hunting. The $y$ axis shows total (i.e. combined) numbers of adults and brood. Each graph depicts only the nest occupancy dynamics from the time at which the deluxe nest was made mediocre. The number of ants occupying the mediocre nest is indicated with circles. The number of ants occupying the good nest is indicated with diamond-shaped symbols

that in those colonies that were able to switch to the finally superior nest there was often severe competition between the emigration processes to the new nests and that the colonies were able to switch because although recruitment to the better nest occurred later it was more powerful and involved stronger positive feedback.

\section{Discussion}

One third of the colonies in experiment 1 did show some flexibility and were able to switch to the good nest even though news of it arrived after they had started carrying nest mates to the mediocre one. Nevertheless, many more ant colonies completed their emigration to the mediocre nest than were able to switch to the belatedly introduced good one (Tables 1 and 2). This implies that there is also some inflexibility after a decision has been made. Comparison of experiment 1 and control 2 suggests strongly that the ants that did switch were not just choosing a newly available nest simply because of its novelty. Rather, switching is quality dependent. This is important because recent work has shown that these ants will choose an unfamiliar new nest over an identical but familiar one when both nests are of low quality. Essentially, the ants can learn about a low quality nest when they have no need to emigrate and can use this information, when they do need a new home, to focus their search elsewhere to have a better chance of finding a new nest of higher quality (Franks et al. 2007).

Experiment 2, in which a deluxe nest degraded during emigration, also suggests a mixture of flexibility (Table 3 ) and inertia (Table 4). However, colonies in experiment 2 seemed to show much more inertia and less flexibility than colonies in experiment 1 . This might be for two reasons. First, in nature nests may rarely degrade during an emigration and so the ants may not be equipped for this possibility. Second, an initially deluxe nest may capture the loyalty of many more scouts than a mediocre nest. Thus, when scouts have discovered a deluxe nest they may lock-on to such a high quality target and few if any continue 
to search for alternatives, which decreases the likelihood of switching. Nevertheless, even in experiment $2,19 \%$ of colonies that chose only one nest switched to the better alternative, even after they had started carrying nest mates to the deluxe nest that was then degraded.

In experiment $1,33 \%$ of all of the colonies that chose only one nest were able to switch to the better alternative even when news of it must have arrived late. This is impressive for two reasons. First, only $62 \%$ of all of the colonies that chose only one nest were able to choose the better one even when both new alternatives were omnipresent, so that they were available for assessment at all times (control 1). Second, although swarming honey bees are able to choose the best new hive even if news of it arrives later than lesser alternatives (Seeley and Buhrman 1999; Britton et al. 2002), they only seem able to switch allegiance before the emigration begins. Here, the ants can sometimes switch allegiance to a better nest even when the emigration has begun and nest mates are being carried actively to a lesser alternative.

The results presented in this paper show that some ants will continue searching for better alternatives even during an emigration. In short, there seems to be a mixture of inertia, locking onto a target, and flexibility, continued search for better alternatives. These ants seem not to be completely prevented from being flexible by misinformation cascades (Giraldeau et al. 2002) in that in some cases, even a few scouts that discover a superior nest late can redirect their colonies' emigrations. The abilities of certain other social insect colonies to switch targets in foraging and house hunting also depends on them having both large numbers of scouts and powerful communication systems (Beckers et al. 1990, 1992; Seeley 1995; Seeley and Buhrman 1999; Camazine et al. 2001; Britton et al. 2002)

It is clear from all of the graphs in Figs. 2 and 3, which show all of the initial nest occupancy data for all of the colonies that could switch in experiments 1 and 2, that these colonies are not simply emigrating fully to the initially superior nest and then, after the first emigration is finished, secondarily emigrating either to a better nest that has just become available or when the initial nest has been degraded. In earlier work, we showed that colonies could "move to improve" from an intact nest to a better one (Dornhaus et al. 2004). However, such "moving to improve" occurs when colonies have no need to emigrate (because their original nest remains intact and of constant quality) and yet they abandon their current nest to occupy a much better one in a single emigration. Here, colonies that switched were already emigrating to one nest and were able to re-route their nest mates to a better alternative whilst the first emigration was still in process.

Inspection of the nest occupancy data for the 10 colonies that switched in experiment 1 shows that in half of the cases (Fig. 2a, b, c, d and e) recruitment to the belatedly introduced superior nest was initially slow but continued to build steadily so that occupancy of that nest eventually overtook that of the initial and inferior nest, whereas in the other 5 colonies (Fig. 2f, g, h, i and j) recruitment to the superior nest was always equal to or much stronger than that to the first nest. The difference between these two sets of colonies may reflect how many scouts were initially committed to the first nest. This was presumably high for the first set of colonies (Fig. 2a, b, c, d and e) and low for the second set (Fig. 2f, g, h, i and j). The results for the 4 colonies that were able to switch in experiment 2 are just as variable with long drawn out competition between the two nests in Fig. $3 \mathrm{a}$ and $\mathrm{b}$ and much more rapid switching in Fig. 3c and 3d. Again this difference probably reflects the numbers of scouts that were committed to the initial nest. Indeed, it seems likely that fewer colonies were able to switch in experiment 2 than in experiment 1 because in the latter many scouts committed fully to the initially very high quality nest and did not change their verdict and allegiance when that nest was experimentally degraded. 
Thus we suspect that the mechanism that enables some colonies to switch to a better alternative nest site, during an emigration to a worse one, involves scouts continuing to search for something better. This could occur because certain scouts are oblivious to the first nest and the on-going emigration to it or because they have actively chosen to search elsewhere because the original nest (as in experiment 1) was of rather low quality. Of course, these two possibilities are not mutually exclusive.

A strategy that involves, at least in part, individual ants actively continuing to search for better alternatives could only work if individuals can make comparisons between the qualities of alternative nests. Earlier work shows that individual ants can do this at least in the first stage of house hunting. Mallon et al. (2001) showed that prior to emigrations individual scouts are able to make direct comparisons of the quality of different nests. Thirty five scouts among the 38 that visited both nests before recruiting to either of them recruited only to the better one (see also Franks et al. 2002). So delayed comparisons of nests by individuals late in the process of emigration should certainly be possible in cognitive terms and switching does seem to be quality dependent. Second, the arenas in which we performed these experiments were relatively small. Hence, it seems unlikely that many scouts would have been ignorant of the presence of the first nest or even the emigration to it. We know that these ants can swiftly search arenas that are many times larger and pick the best-of-N available nests (Franks et al. 2003a, 2006b). Third, there is no relationship between colony size and the ability of colonies to switch. This suggests that the ability to switch depends more on the abilities of individuals than the number of individuals. Fourth, the ants seem much more likely to switch if news of a better alternative arrived late (experiment 1) than if a high quality nest degenerates during an emigration (experiment 2). This might suggest that scouts only continue searching if the first alternative they encounter is relatively poor (experiment 1 and see also Mallon et al. 2001). In other words, any tendency to search elsewhere is reduced upon first encountering a nest of really high quality (and that tendency is not updated quickly if the quality of the selected target nest changes during an emigration; experiment 2). Future experimental work will focus on the behavior of individual scouts as the likely mechanism that enables colonies to switch.

\section{Conclusions}

One focus of current research in biology is to identify models of collective decisionmaking (Couzin et al. 2005). Macroscopic models have been developed for house-hunting by T. albipennis and T. curvispinosus ant colonies (Pratt et al. 2005; Marshall et al. 2006; Pratt and Sumpter 2006). Similarly, engineering research is profiting from and, to a certain extent, helping to drive advances in the understanding of collective decision-making. The house-hunting models mentioned above have already inspired the design of novel computer algorithms applicable to mobile ad hoc networks (Peysakhov and Regli 2005; Cicirello et al. 2005; Peysakhov et al. 2006) and swarm robotics (Berman et al. 2006; Berman et al. 2007).

Previous work has considered the applicability of house-hunting as an 'anytime algorithm' (Dean and Boddy 1988) for engineering, for example in process migration strategies for grid-computing (Marshall et al. 2006). An anytime algorithm is one that is able to produce an approximate answer on demand (in other words, at any time). The longer the algorithm is executed, the more precise the answer. Here we have extended this endeavor by investigating collective decision-making in dynamic environments where new priorities occur while the collective reorganizes itself in response to an earlier decision. The ability 
to deal with such situations can be of great use for many control and decision problems in engineering; indeed it was consideration of the aforementioned process migration problem that motivated the present study. In the process migration problem, computational processes must migrate between different nodes of computer networks in order to find the best computational resources available, and thereby minimize their execution time. As computational load and availability of nodes varies unpredictably, a computer network can be considered a highly dynamic environment, similar to that presented experimentally to the ants in this paper.

Overall, our results show that even when colonies have locked onto a target-a suitable new home-and have committed to it by carrying nest mates there in an active emigration, some can switch to better alternatives. This occurred both when good news arrived late and, albeit much less frequently, when a good decision turned bad.

In general our results show one of the great benefits of communal living - not just the sharing of timely and accurate information but that certain members of the society may continue to explore for better alternatives.

Acknowledgements N.R.F. \& R.G. thank the BBSRC (grant E19832). N.R.F. \& J.A.R.M. thank the EPSRC (grant GR/S78674/01). A.D. was supported in Bristol by a DFG, Emmy Noether fellowship. We also wish to thank Tim Kovacs and the Ant Lab at Bristol for very helpful discussion. We express our gratitude to two anonymous reviewers for exceptionally insightful and helpful comments.

\section{References}

Beckers, R., Deneubourg, J. L., Goss, S., \& Pasteels, J. M. (1990). Collective decision making through food recruitment. Insectes Sociaux, 37, 258-267.

Beckers, R., Deneubourg, J. L., \& Goss, S. (1992). Trail laying behavior during food recruitment in the ant Lasius niger (L.). Insectes Sociaux, 39, 59-72.

Benjamini, Y., \& Yekutieli, D. (2001). The control of the false discovery rate in multiple testing under dependency. Annals of Statistics, 29, 1165-1188.

Berman, S., Halász, Á., Kumar, V., \& Pratt, S. (2006). Algorithms for the analysis and synthesis of a bioinspired swarm robotic system. In Lecture notes in computer science: Vol. 4433. Proceedings of the 2 nd SAB 2006 international workshop on swarm robotics (pp. 56-70). Berlin: Springer.

Berman, S., Halász, Á., Kumar, V., \& Pratt, S. (2007). Bio-inspired group behaviors for the deployment of a swarm of robots to multiple destinations. In Proceedings of the 2007 IEEE international conference on robotics and automation (pp. 2318-2323). Los Alamitos: IEEE Computer Society Press.

Bonabeau, E., Dorigo, M., \& Theraulaz, G. (1999). Swarm intelligence: from natural to artificial systems (p. XII+307). New York: Oxford University Press.

Bourke, A. F. G., \& Franks, N. R. (1995). Social evolution in ants. Monographs in behavioral ecology (p. XIV+529). Princeton: Princeton University Press.

Britton, N. F., Franks, N. R., Pratt, S. C., \& Seeley, T. D. (2002). Deciding on a new home: how do honeybees agree? Proceedings of the Royal Society of London Series B, 269, 1383-1388. doi:10.1098/rspb.2002.2001.

Camazine, S., Deneubourg, J.-L., Franks, N. R., Sneyd, J., Theraulaz, G., \& Bonabeau, E. (2001). Selforganization in biological systems. Princeton: Princeton University Press.

Chittka, L., Dyer, A. G., Bock, F., \& Dornhaus, A. (2003). Bees trade off foraging speed for accuracy. Nature, $424,388$.

Cicirello, V., Peysakhov, M., Anderson, G., Naik, G., Tsang, K., Regli, W., \& Kam, M. (2005). Designing dependable agent systems for mobile wireless networks. IEEE Intelligent Systems, 19, 39-45. doi:10.1109/MIS.2004.41.

Conradt, L., \& Roper, T. J. (2005). Consensus decision making in animals. Trends in Ecology and Evolution, 20, 449-456. doi:10.1016/j.tree.2005.05.008.

Couzin, I. D., Krause, J., Franks, N. R., \& Levin, S. A. (2005). Effective leadership and decision-making in animal groups on the move. Nature, 433, 513-516. doi:10.1038/nature03236.

Dean, T. L., \& Boddy, M. (1988). An analysis of time-dependent planning. In T. M. Mitchell \& G. Smith (Eds.), Proceedings of the seventh national conference on artificial intelligence (pp. 49-54). Menlo Park: AAAI Press. 
Dechaume-Moncharmont, F.-X., Dornhaus, A., Houston, A. I., McNamara, J. M., Collins, E. J., \& Franks, N. R. (2005). The hidden cost of information in collective foraging. Proceedings of the Royal Society B, 272, 1689-1695. doi:10.1098/rspb.2005.3137.

Dornhaus, A., Franks, N. R., Hawkins, R. M., \& Shere, H. N. S. (2004). Ants move to improve-colonies of Leptothorax albipennis emigrate whenever they find a superior nest site. Animal Behaviour, 67, 959963.

Dornhaus, A., \& Franks, N. R. (2006). Colony size affects collective decision-making in the ant Temnothorax albipennis. Insectes Sociaux, 53, 420-427. doi:10.1007/s0040-006-0887-4.

Dornhaus, A., Collins, E. J., Dechaume-Moncharmont, F.-X., Houston, A. I., Franks, N. R., \& McNamara, J. M. (2006). Paying for information: partial loads in central place foragers. Behavioral Ecology and Sociobiology, 61, 151-161. doi:10.1007/s00265-006-0246-5.

Franks, N. R. (1989). Army ants: a collective intelligence. American Scientist, 77, 138-145.

Franks, N. R., \& Richardson, T. (2006). Teaching in tandem-running ants. Nature, 439, 153. doi:10.1038/ 439153a.

Franks, N. R., Pratt, S. C., Mallon, E. B., Britton, N. F., \& Sumpter, D. J. T. (2002). Information flow, opinion-polling and collective intelligence in house-hunting social insects. Philosophical Transactions of the Royal Society of London Series B, 357, 1567-1583.

Franks, N. R., Dornhaus, A., Fitzsimmons, J. P., \& Stevens, M. (2003a). Speed versus accuracy in collective decision-making. Proceedings of the Royal Society of London Series B, 270, 2457-2463. doi:10.1098/rspb.2003.2527.

Franks, N. R., Mallon, E. B., Bray, H. E., Hamilton, M. J., \& Mischler, T. C. (2003b). Strategies for choosing among alternatives with different attributes: exemplified by house-hunting ants. Animal Behaviour, 65, 215-223. doi:10.1006/anbe.2002.2032.

Franks, N. R., Dornhaus, A., Best, C. S., \& Jones, E. L. (2006a). Decision-making by small \& large house hunting ant colonies: one size fits all. Animal Behaviour, 72, 611-616. doi:10.1016/ j.anbehav.2005.11.019.

Franks, N. R., Dornhaus, A., Metherell, B. G., Nelson, T. R., Lanfear, S. A. J., \& Symes, W. S. (2006b). Not everything that counts can be counted: Ants use multiple metrics for a single nest trait. Proceedings of the Royal Society of London Series B, 273, 165-169. doi:10.1098/rspb.2005.3312.

Franks, N. R., Hooper, J. W., Dornhaus, A., Aukett, P. J., Hayward, A. L., \& Berghoff, S. M. (2007). Reconnaissance and latent learning in ants. Proceedings of the Royal Society of London Series B, 274, 1505-1509. doi:10.1098/rspb.2007.0138.

Giraldeau, L.-A., Valone, T. J., \& Templeton, J. J. (2002). Potential disadvantages of using socially acquired information. Philosophical Transactions of the Royal Society of London Series B, 357, 1559-1566. doi:10.1098/rstb.2002.1065.

Janson, S., Middendorf, M., \& Beekman, M. (2007). Searching for a new home-scouting behavior of honeybee swarms. Behavioral Ecology, 18, 384-392. doi:10.1093/beheco/ar1095.

King, A. J., \& Cowlishaw, G. (2007). When to use social information: the advantage of large group size in individual decision making. Biology Letters, 3, 137-139. doi:10.1098/rsbl.2007.0017.

Mallon, E. B., Pratt, S. C., \& Franks, N. R. (2001). Individual and collective decision-making during nest site selection by the ant Leptothorax albipennis. Behavioral Ecology and Sociobiology, 50, 352-359. doi: $10.1007 / \mathrm{s} 002650100377$.

Marshall, J. A. R., Dornhaus, A., Franks, N. R., \& Kovacs, T. (2006). Noise, cost and speed-accuracy tradeoffs: decision-making in a decentralized system. Journal of the Royal Society: Interface, 3, 243-254. doi:10.1098/rsif.2005.0075.

Pearson, B., Raybould, A. F., \& Clarke, R. T. (1995). Breeding behavior, relatedness and sex- investment ratios in Leptothorax tuberum Fabricius. Entomologia Experimentalis et Applicata, 75, 165-174.

Peysakhov, M. D., \& Regli, W. C. (2005). Ant inspired server population management in a service based computing environment. In Proceedings of the 2005 IEEE swarm intelligence symposium (pp. 357364). Los Alamitos: IEEE Computer Society Press. doi:10.1109/SIS. 2005.1501643.

Peysakhov, M., Dugan, C., Modi, P. J., \& Regli, W. (2006). Quorum sensing on mobile ad-hoc networks. In Proceedings of the 5th international joint conference on autonomous agents and multiagent systems (pp. 1104-1106). New York: ACM. doi:10.1145/1160633.1160831.

Planqué, R., Dornhaus, A., Franks, N. R., Kovacs, T., \& Marshall, J. A. R. (2006). Weighting waiting in collective decision-making. Behavioral Ecology and Sociobiology, 61, 347-356. doi:10.1007/s00265-006-0263-4.

Pratt, S. C., \& Sumpter, D. J. T. (2006). A tunable algorithm for collective decision-making. Proceedings of the National Academy of Sciences of the United States of America, 103, 15906-15910. doi:10.1073/pnas.0604801103.

Pratt, S. C., Mallon, E. B., Sumpter, D. J. T., \& Franks, N. R. (2002). Quorum sensing, recruitment, and collective decision-making during colony emigration by the ant Leptothorax albipennis. Behavioral Ecology and Sociobiology, 52, 117-127. doi:10.1007/s00265-002-0487-x. 
Pratt, S. C., Sumpter, D. J. T., Mallon, E. B., \& Franks, N. R. (2005). An agent-based model of collective nest choice by the ant Temnothorax albipennis. Animal Behaviour, 70, 1023-1036. doi:10.1016/j.anbehav.2005.01.022.

Seeley, T. D. (1995). The wisdom of the hive. Cambridge: Harvard University Press.

Seeley, T. D., \& Buhrman, S. (1999). Group decision making in swarms of honey bees. Behavioral Ecology and Sociobiology, 45, 19-31. doi:10.1007/s002650050536.

Visscher, P. K. (2007). Group decision making in nest-site selection among social insects. Annual Review of Entomology, 52, 255-275. doi:10.1146/annurev.ento.51.110104.151025. 